\title{
Effect of gas jet angle on primary breakup and droplet size applying coaxial gas-assisted atomizers
}

\author{
Simon Wachter, ${ }^{* 1}$ Tobias Jakobs ${ }^{1}$ and Thomas Kolb ${ }^{1,2}$ \\ ${ }^{1}$ Karlsruhe Institute of Technology, Institute for Technical Chemistry, 76344 Eggenstein- \\ Leopoldshafen, Germany \\ ${ }^{2}$ Karlsruhe Institute of Technology, Engler-Bunte-Institute, 76131 Karlsruhe, Germany \\ ${ }^{*}$ Corresponding author email: simon.wachter@kit.edu
}

\begin{abstract}
This study investigates the influence of gas jet angle on primary jet breakup and the resulting droplet size distribution for coaxial gas-assisted atomizers. In industrial applications, the gas jet of these atomizers are typically angled towards the liquid jet, whereas in most spray investigations in literature, parallel flow configurations are used. To enable a detailed analysis of the influence of the gas jet angle, three atomizers with angles of $0^{\circ}, 15^{\circ}$ and $30^{\circ}$ were examined. Other geometric parameters, such as liquid jet diameter, gas gap width and wall thickness were kept constant. For each atomizer, two gas velocities at constant liquid mass flow were investigated i.e., two gas-to-liquid ratios (GLRs). An additional set of experiments was performed at increased system pressure using three atomizers with identical gas jet angles, but with an adapted gas orifice area in order to keep gas velocity, GLR and momentum flow ratio constant for all pressure levels. Water and a glycerol/water-mixture were applied in order to investigate the influence of liquid viscosity. The primary breakup process was monitored by a high-speed camera, whereas the resulting droplet size was detected using a phase-Doppler anemometer. For all system pressures and liquid viscosities under investigation, a distinct influence of gas jet angle on primary breakup as well as on resulting droplet size distribution was observed for low gas velocity.
\end{abstract}

\section{Keywords}

Gas-assisted atomizer, angled gas jet, atomizer geometry, viscosity, system pressure

\section{Introduction}

High-pressure entrained flow gasification (EFG) is a key technology in the realization of a future, carbon-neutral circular economy, as it is an enabling technology to close the carbon cycle through the conversion of biomass and waste-based feedstocks into syngas $\left(\mathrm{CO}+\mathrm{H}_{2}\right)$. EFG typically uses oxygen as gasification agent, which also serves as atomization agent; as a result gas-to-liquid ratios (GLRs) $<1$ are applied [1]. Coaxial gas-assisted atomizers are typically used, due to their advantages with respect to abrasion and clogging. Faragò and Chigier [2] performed detailed investigations concerning breakup morphology, where liquid was provided from a central tube with a concentric gas stream. The breakup of water was classified into spray regimes, showing a transition from the Rayleigh-type to the membrane and fiber type breakup with increasing Weber number at constant liquid Reynolds number. Lasheras and Hopfinger [3] expanded the regime classification for different momentum flux ratios. Studies on the droplet size that resulted from this configuration applied Newtonian viscous liquids in a viscosity range of $\eta_{\text {liq }}=1-100 \mathrm{mPa} \cdot \mathrm{s}$ and $\mathrm{GLR}=1-12$, and were conducted by Lorenzetto [4], Jasuja [5], Rizk [6] and Walzel [7]. For GLR $<1$ and 4 liquid viscosities, Sänger et al. [8] detected 2 different primary instability modes (flapping and pulsating) that influenced the resulting drop size.

In the aforementioned studies, high-velocity annular gas streams with a straight exit channel were typically utilized. Nonetheless, industrial applications typically use a converging exit (straight inner, angled outer wall) or an angled gas exit (inner and outer wall angled) [9-13]. 
The change from straight to converging gas-exiting channels and its effect on the resulting droplet size was first reported by Hardalupas et al. [14]. In their experiments, the straight exit was changed to a converging angle of $\alpha=28^{\circ}$. As a result, a decrease in droplet size over the entire spray cone, depending on the gas-to-liquid velocity ratio $v_{\text {gas }} / v_{\text {liq }}$, was identified. An increase in the gas-to-liquid velocity ratio above 50 revealed no further changes in droplet size [14]. Additionally, Varga et al. [15] compared a nozzle with a straight gas channel with a converging gas channel for varying $v_{\text {gas }}=50-165 \mathrm{~m} \cdot \mathrm{s}^{-1}$ and constant $v_{\text {liq }}=1.7 \mathrm{~m} \cdot \mathrm{s}^{-1}$. In contrast to the previously-mentioned study, a constant reduction of droplet size of $\Delta \mathrm{ld}_{32} \approx 18$ $\mu \mathrm{m}$ was detected (variance in droplet size of $19-33 \%$ ) for all operating conditions when changing from the straight nozzle exit to a converging exit channel. Varga et al. [15] denoted that the reduction in droplet size could be attributed to a reduction in the boundary layer thickness when utilizing the converging gas channel. In the studies mentioned, straight gas channels were compared to converging gas channels, which feature an inner straight wall and outer wall with a distinct angle. Investigations of angled gas channels (inner and outer walls), as well as a variation and comparison of the angle with a straight gas channel have not been reported jet.

In this context, this study is focused on the influence of the gas channel angle on resulting droplet size distribution and primary jet breakup at operating conditions relevant for EFG. A high-speed camera was used to detect the primary breakup and a phase Doppler analyzer (PDA) for measuring the local droplet velocity and size. 3 different gas channel angles were investigated at 2 gas velocities, 2 dynamic viscosities and 2 system pressure levels while applying pressure-adapted atomizers [16]. Additional measurements using particle image velocimetry were also performed in order to obtain a deeper insight into the gas flow field in the near-nozzle region.

\section{Experimental setup}

The experimental setup consists of the pressurized atomization test rig (PAT), a phase Doppler analyzer, a high-speed camera and 6 different atomizers. A schema of the PAT spray test rig with exhaust air system and a horizontal cross-sectional view $(A-A)$ is presented in Wachter et al. [17].

The pressure chamber has an internal diameter of $300 \mathrm{~mm}$ and a total height of $3000 \mathrm{~mm}$. It is designed for operation at system pressures of up to $p_{s y s}=21$ bar. The external-mixing twinfluid atomizer is mounted on the axially (z-direction) movable twin-fluid lance, which is fed by one of the two eccentric screw pumps with liquids that featured viscosities of up to $\eta_{\text {liq }}=1000$ $\mathrm{mPa}$. The liquid mass flow can be controlled in the range of P1: $\dot{\mathrm{M}}_{\text {liq }}=10-60 \mathrm{~kg} \cdot \mathrm{h}^{-1} / \mathrm{P} 2$ : $\dot{M}_{\text {liq }}=60-200 \mathrm{~kg} \cdot \mathrm{h}^{-1}$ using different screw pumps. The liquid mass flow and density are measured using a Coriolis flow meter with an uncertainty of $<0.5 \%$. The compressed air volume flow $\dot{V}_{\text {gas }}$ is detected by a turbine meter with a measuring range of $\dot{V}_{\text {gas }}=0.85-25$ $\mathrm{m}^{3} \cdot \mathrm{h}^{-1}$ and an uncertainty of $<0.5 \%$. A recalculation of volume to mass flow is done using the locally-measured gas temperature and pressure at the measurement turbine. To ensure welldefined nozzle inlet conditions, the liquid can be stirred and tempered in the range of $T=10$ ${ }^{\circ} \mathrm{C}-50{ }^{\circ} \mathrm{C}$. The test rig is equipped with three glass windows (no inclusions or cords) that allow for optical access to the spray chamber and avoid any disturbances to the laser beam. Two optical ports are located at $\Phi_{\mathrm{R}}=0^{\circ}$ and $70^{\circ}$ to enable Phase Doppler measurements in scattering mode with - preferably - the highest intensity (first-order refraction) [18]. The third optical port is positioned at $\Phi_{R}=180^{\circ}$ to allow for spray investigations in backlight mode using optical measurement systems. In order to ensure protection from window deposits at the $\Phi_{R}$ $=70^{\circ}$ window location, a wiper is used between each measurement section, which employs compressed air for movement. A flow-straightener (honeycomb structure) is located below the 
measuring plane to avoid recirculation of droplets. For all experiments, pressurized air at 20 ${ }^{\circ} \mathrm{C}$ was utilized as atomization agent.

The experiments were conducted with 3 coaxial gas-assisted atomizers - for each pressure range investigated, as shown in Figure 1 , exemplarily, for $p_{\text {sys }}=1$ bar. In all cases, the central tube had a diameter of $D_{\text {liq }}=2.0 \mathrm{~mm}$. To minimize flow induced turbulence, the wall thickness $b$ between the inner and outer orifice was set to $b=0.1 \mathrm{~mm}$. The nozzles designed for $p_{\text {sys }}=$ 1 bar had a gas orifice diameter of $D_{\text {gas }}=7.96 \mathrm{~mm}$, whereas the diameter was reduced to $D_{\text {gas }}$ $=3.18 \mathrm{~mm}$ for the nozzles designed for $p_{\text {sys }}=11$ bar. This concept allows for solely varying the system pressure, keeping all other operating conditions constant ( $\left.v_{\text {liq }}, v_{\text {gas }}, G L R, \dot{M}_{\text {liq }}, \dot{M}_{\text {gas }}\right)$, as according to Wachter et al. [16].
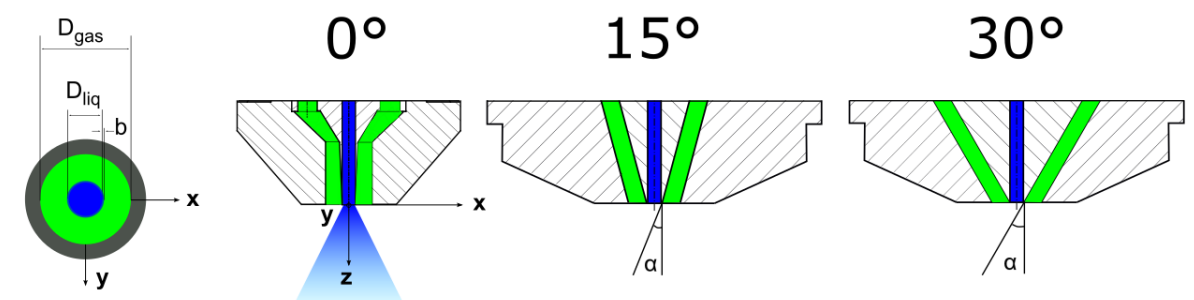

Figure 1. Scheme of the external-mixing atomizers for $p_{\text {sys }}=1$ bar and 3 different gas channel angles $\alpha=0,15$ and $30^{\circ}$.

Table 1. Physical properties of applied liquids at $20^{\circ} \mathrm{C}$ and atmospheric pressure.

\begin{tabular}{|c|ccc|}
\cline { 2 - 4 } \multicolumn{1}{c|}{} & $\eta_{\text {liq }}$ in $\mathrm{mPa} \cdot \mathrm{s}$ & $\sigma$ in $\mathrm{kg} \cdot \mathrm{s}^{-2}$ & $\rho_{\text {liq }}$ in $\mathrm{kg} \cdot \mathrm{m}^{-3}$ \\
\hline Water & 1 & 0.0728 & 998 \\
Glycerol/water (89.5 wt.\%) & 200 & 0.0642 & 1233 \\
\hline
\end{tabular}

For the investigation of liquid viscosity $\eta_{\text {liq }}$ on the primary jet breakup and droplet size, water and a glycerol/water - mixture were used. The surface tension and density of the two liquids applied are almost constant (see Table 1). The liquid viscosity was quantified by applying a Physica MCR 101 rheometer from Anton Paar with a Searle-type measuring system [19]. The surface tension and density were measured by means of an EasyDyne tensiometer from Krüss that employed the Du Noüy ring [20] and weighing methods, respectively. Table 1 displays the mass ratio, viscosity, surface tension and density for both liquids at $20^{\circ} \mathrm{C}$ and atmospheric pressure.

A high-speed camera was placed in the nozzle nearfield for the qualitative observation of the primary breakup of the liquid jet. The camera featured a frame rate of $3.6 \mathrm{kHz}$ at a resolution of $1024 \times 1024$ pixel and frame rates of up to $500 \mathrm{kHz}$ at reduced resolution. A lens with a focal length of $f_{H G}=105 \mathrm{~mm}$ was used to capture the primary breakup morphologies. In this study, the frame rate was set to at least $7.5 \mathrm{kHz}$ with the respective resolutions given in the images. The images were captured via backlight illumination of the region of interest by means of a special lighting setup of $9 \times 4500 \mathrm{~lm}$. Owing to the high intensity and homogeneous distribution of the light, very short exposure times ( $\left.\mathrm{t}_{\mathrm{Exp}} \sim 7 \mu \mathrm{s}\right)$ were employed. A set of at least 2000 high-speed images was recorded at every operating condition, along with a background reference image without the liquid flow.

In addition, the same camera was used at $z=200 \mathrm{~mm}$ in order to: (i) optimize the PDA hardware settings (receiver mask); (ii) for the sphericity check of the droplets in the measuring plane to ensure the reliability of the PDA data; (iii) qualitatively confirm the tendencies measured by the PDA; and (iv) as a validation tool for the PDA data in order to eliminate the deviations arising from the Gaussian beam effect [21]. 
Table 2. Settings of the Fiber PDA evaluated by the sensitivity analysis.

\begin{tabular}{|c|cc|c|cc|}
\hline Parameters & Values & Unit & Parameters & Values & Unit \\
\hline Transmitter focal length & 1000 & $\mathrm{~mm}$ & Laser wavelength & 561 & $\mathrm{Nm}$ \\
Receiver focal length & 1000 & $\mathrm{~mm}$ & Laser power & 40 & $\mathrm{~mW}$ \\
Beam expander ratio & 1 & - & Off-axis angle & 70 & $\circ$ \\
Receiver slit width & 200 & $\mu \mathrm{m}$ & Frequency shift & 80 & $\mathrm{MHz}$ \\
\hline
\end{tabular}

The measurement of droplet size within the spray cone at a high spatial and temporal resolution was performed with a Fiber PDA by Dantec Dynamics at $z=200 \mathrm{~mm}$. For data collection the PDA was operated in a forward scattering arrangement, with the refraction mode (1st - order) using the asymmetrical Mask B. To guarantee for the detection of large droplets, as expected by the atomization of highly viscous liquids and avoid sizing errors due to the Gaussian beam effect according to Araneo [21], the PDA was set as displayed in Table 2. With this optical configuration, the PDA system enabled the detection of droplets with a minimum size of $1 \mu \mathrm{m}$ and maximum size of $1357 \mu \mathrm{m}$ in the case of water, and $1380 \mu \mathrm{m}$ in that of the glycerol/water mixtures, related to the refractive index of the liquid [18]. To improve the PDA settings, a sensitivity study, as described in [22], was performed.

The receiver and transmitter were mounted on a traverse, which guarantees for spatiallyreproducible operation $<0.1 \mathrm{~mm}$ and enabled droplet size measurements at distinct positions within the spray cone. The measurements were recorded at several radial positions (traverse along the $\mathrm{x}$ - axis) with a radial increment of $\Delta \mathrm{x}=2-4 \mathrm{~mm}$ depending on the measurement position. In order to ensure a reliable database for every radial position during PDA measurements as a termination criterion, the sample size and measurement time were set to 50,000 droplets or 60 seconds, respectively. At least 5000 droplets were detected at every radial position. The raw data from the manufacturer software were used to compute arithmetic means and statistical data, as well as additional information using the toolbox SprayCAT; see Wachter [17]. For the global characterization of the spray, the computation of a global characteristic diameter, i.e., mass-weighted integral Sauter mean diameter $\mathrm{Id}_{32, \mathrm{~m}}$, was carried out by means of a weighted average, including all measurement positions of a radial profile at a fixed axial position $z$. The integral Sauter mean diameter $\mathrm{Id}_{32, \mathrm{~m}}$ was calculated according to Equation (1), below, based on the local volume mean diameter $D_{30, i}$ and local surface mean diameter $D_{20, i .}$ These diameters were weighted by local mass flux $\dot{m}_{i}$ and the annulus area $A_{i}$, corresponding to the measurement position $i$ along the radial axis $x_{1} \leq x_{i} \leq x_{N}$ with $N$ measurement positions.

$$
\operatorname{Id}_{32, \mathrm{~m}}=\frac{\sum_{\mathrm{i}=1}^{\mathrm{N}} \mathrm{D}_{30, \mathrm{i}}^{3} \dot{\mathrm{m}}_{\mathrm{i}} \mathrm{A}_{\mathrm{i}}}{\sum_{\mathrm{i}=1}^{\mathrm{N}} \mathrm{D}_{20, \mathrm{i}}^{2} \dot{\mathrm{m}}_{\mathrm{i}} \mathrm{A}_{\mathrm{i}}}
$$

Further information concerning the computation of global size distribution and droplet size moments can be obtained from DIN SPEC 91325, as well as from Albrecht [18]. Each measurement series was repeated at least 3 times. For each operating condition and nozzle configuration, the rotational symmetry of the spray cone was proven, taking a full radial profile in a first set of experiments. After the rotational symmetry was proven, the following repetition measurements were performed, taking half profiles from the spray edge to the centre at $x=0$ $\mathrm{mm}$.

Particle image velocimetry (PIV) measurements were performed with a PIV system from Dantec Dynamics that consisted of a CCD camera and a Nd:YAG double-pulse laser for 
illumination. The camera was equipped with a $f=105 \mathrm{~mm}$ lens and spacer rings, resulting in a field of view of $28 \times 28 \mathrm{~mm}^{2}$ at a resolution of 4 megapixels. The gas phase was seeded with di-ethyl-hexyl-sebacat (DEHS) droplets in the size range of $d_{D E H S}=1-5 \mu \mathrm{m}$ in order to follow the gas phase undisturbed [23], using a seeding generator from LaVision. As liquid flow, while PIV measurements, would lead to a strong reflection that overexposes the camera sensor; when hit by the laser sheet, a black-coloured pin with an identical diameter and $10 \mathrm{~mm}$ in length was used to replace the liquid jet for the measurements. Each resulting image was averaged out of 50 double images.

\section{Results and Discussion}

In order to investigate the influence of the gas channel angle on resulting droplet size and primary breakup for the coaxial gas-assisted atomizers described above, the experiments were conducted using the operating conditions presented in Table 3 . As the liquid mass flow was set constant at $\dot{M}_{\text {liq }}=20 \mathrm{~kg} \cdot \mathrm{h}^{-1}$. Liquid velocity changed from $V_{\text {liq }}=1.77 \mathrm{~m} \cdot \mathrm{s}^{-1}$ for water to $V_{\text {liq }}=1.45 \mathrm{~m} \cdot \mathrm{s}^{-1}$ for the glycerol $/$ water mixture with $\eta_{\text {liq }}=200 \mathrm{mPa} \cdot \mathrm{s}$. The system pressure was varied between $p_{\text {sys }}=1$ and 11 bar, applying pressure-adapted nozzles.

Table 3. Operating conditions of the experiments for all of the investigated gas channel angles.

\begin{tabular}{|c|c|c|c|}
\hline$\dot{M}_{\text {liq }}$ in $\mathrm{kg} \cdot \mathrm{h}^{-1}$ & $\dot{\mathrm{M}}_{\text {gas }}$ in $\mathrm{kg} \cdot \mathrm{h}^{-1}$ & $\mathrm{v}_{\text {gas }}$ in $\mathrm{m} \cdot \mathrm{s}^{-1}$ & $\mathrm{GLR}$ \\
\hline 20 & $12 / 20$ & $60 / 100$ & $0.6 / 1.0$ \\
\hline
\end{tabular}

\section{(i) Influence of the gas channel angle on the droplet size and primary breakup}

For the quantitative comparison of the resulting droplet size while utilizing different gas channel angles, radial PDA measurements were first performed for the higher liquid viscosity $\eta_{\text {liq }}=200 \mathrm{mPa} \cdot \mathrm{s}$ and angles $\alpha=0-30^{\circ}$. Applying liquids with higher viscosity facilitates a better insight into the jet breakup phenomena, due to the damping effects of the viscosity. For the experiments in chapter (i), $A_{\text {gas }}, p_{\text {sys }}$ and $\rho_{\text {gas }}$ were not changed. The measured values for $\mathrm{d}_{32}$ at $\mathrm{v}_{\text {gas }}=60 \mathrm{~m} \cdot \mathrm{s}^{-1}$ and $\mathrm{p}_{\text {sys }}=1$ bar are shown in Figure 2 (left).

An increase in gas channel angle leads to a decrease in droplet size, especially at the spray center. This result corresponds to the results of Hardalupas et al. [14] for converging gas channels, as the gas velocity ratio was $v_{\text {gas }} / v_{\text {liq }}=41.4<50$. Typically, a decrease in droplet size is attributed to an increase in the aerodynamic forces, mostly as described by the gas momentum flow $\left(\mathrm{J}_{\text {gas }}=\rho_{\text {gas }} \cdot \mathrm{v}_{\text {gas }}{ }^{2} \cdot \mathrm{A}_{\text {gas }}\right)$. In order to understand this effect, the radial mean velocity profiles of the droplets are also displayed in Figure 2. For an increasing gas channel angle from $\alpha=0$ to $30^{\circ}$, a significant increase in the droplet mean velocity of $\Delta v_{z}=3 \mathrm{~m} \cdot \mathrm{s}^{-1}$ could be detected at the spray center. As the gas velocity at the nozzle orifice remained constant at $v_{\text {gas }}=60 \mathrm{~m} \cdot \mathrm{s}^{-1}$ for every gas channel angle, a double-pulse PIV was used to detect differences in the flow field of the exiting gas phase, which may be correlated to a change in the gas channel angle. In order to get a better impression of the flow field close to the nozzle orifice, in a first set of PIV measurements 50 double-pulse images for each operating condition were taken. Figure 2 (right) shows the resulting absolute gas phase velocity $v_{a b s}$ for the different gas channel angles at $v_{\text {gas }}=60 \mathrm{~m} \cdot \mathrm{s}^{-1}$ and $p_{\text {sys }}=1$ bar. As can be seen from the absolute gas phase velocities, the high-velocity gas phase that emerged from the nozzle with $v_{\text {gas }}=60 \mathrm{~m} \cdot \mathrm{s}^{-1}$ was calculated. For $\alpha=0^{\circ}$, the gas stream sheared the pin without a distinct impact and velocity slightly decreased with further distance from the nozzle orifice. In contrast to this, for $\alpha=30^{\circ}$, the gas phase hits the pin, whereby the cross-sectional area of the gas flow was reduced, resulting in an increase in velocity in the range of $\Delta v_{\text {gas }} \approx 20 \mathrm{~m} \cdot \mathrm{s}^{-1}$. The decrease in the shear layer thickness corresponds to the findings of Varga et al. [15], who proposed this effect when utilizing converging nozzle geometries. 

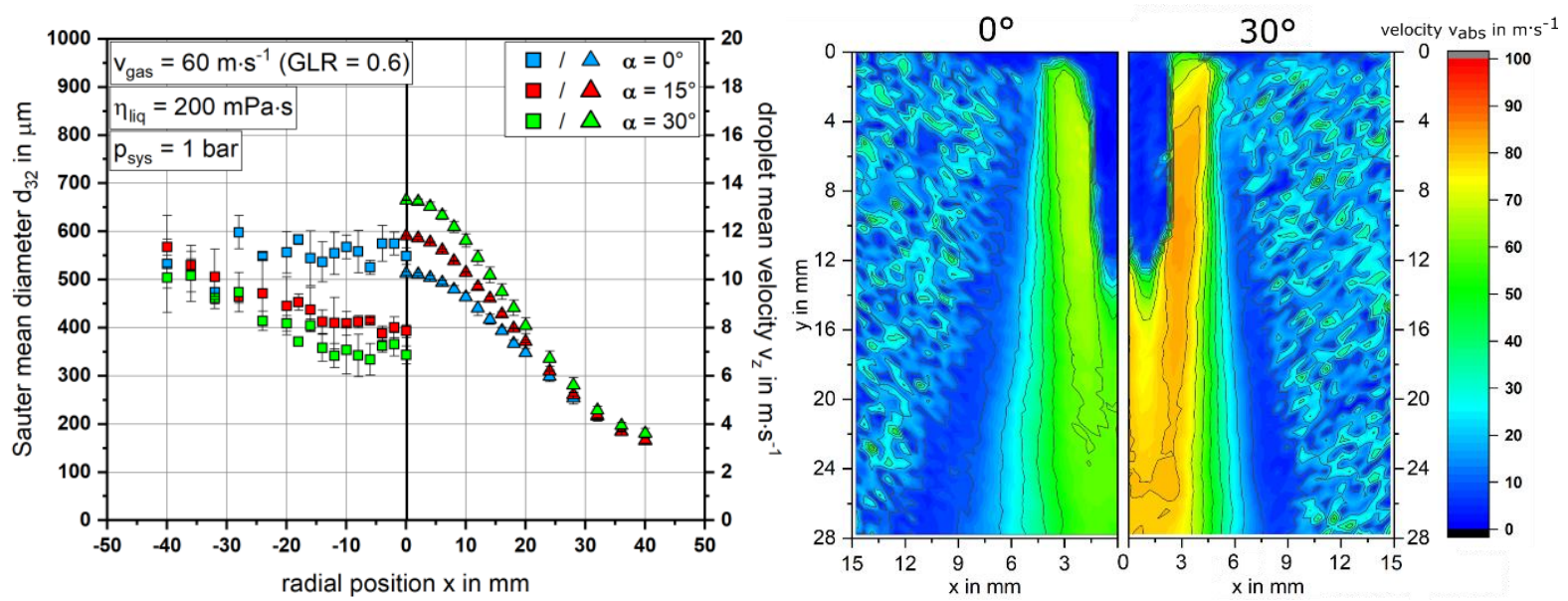

Figure 2. Radial measurement of $d_{32}$ and $v_{z}$ for $\alpha=0,15$ and $30^{\circ}$ at $v_{\text {gas }}=60 \mathrm{~m} \cdot \mathrm{s}^{-1}(\mathrm{GLR}=0.6)$, $\eta_{\text {liq }}=200 \mathrm{mPa} \cdot \mathrm{s}$ and $p_{\text {sys }}=1$ bar (left); PIV measurements of the seeded gas phase at the nozzle orifice for different gas channel angles $\left(\alpha=0,30^{\circ}\right)$ at $v_{\text {gas }}=60 \mathrm{~m} \cdot \mathrm{s}^{-1}$ and $p_{\text {sys }}=1$ bar (right).

The gas velocity remains high even after the impact and the alignment over the entire measurement length in z-direction. The noted impact on the liquid jet, as well as the reduced shear layer thickness, leads to an increase in the aerodynamic forces, which increases droplet velocities and decreases droplet size.

The effect of gas channel angle on primary breakup is depicted by high-speed camera images in Figure 3 (left) at the investigated $\alpha=0-30^{\circ}, v_{\text {gas }}=60 \mathrm{~m} \cdot \mathrm{s}^{-1}, \eta_{\text {liq }}=200 \mathrm{mPa} \cdot \mathrm{s}$ and $\mathrm{p}_{\text {sys }}=1$ bar.
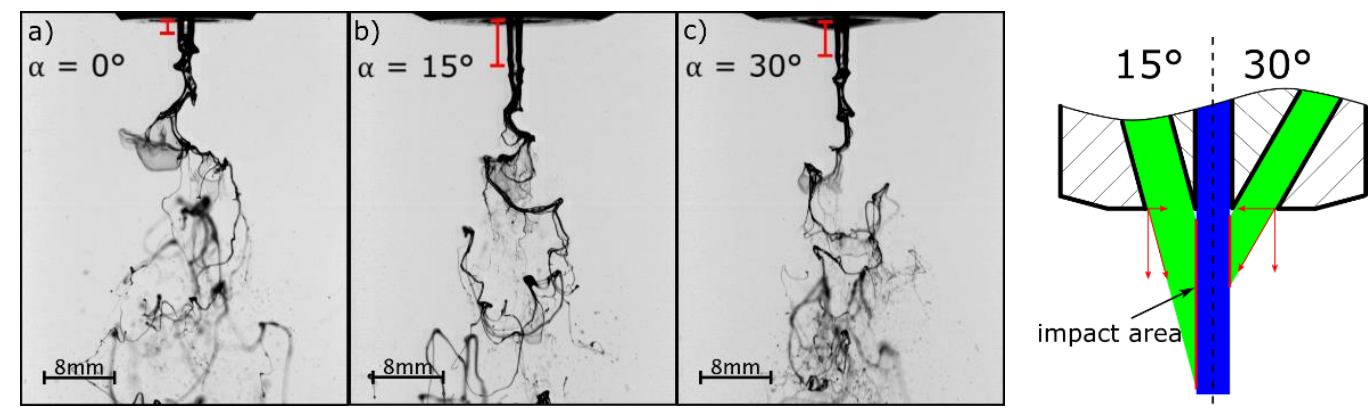

Figure 3. High-speed camera images of the primary breakup at varying gas channel angles $\alpha=0,15$ and $30^{\circ}$, with the atomizers applied at $v_{\text {gas }}=60 \mathrm{~m} \cdot \mathrm{s}^{-1}$, $\mathrm{p}_{\text {sys }}=1$ bar, with $\eta_{\text {liq }}=200 \mathrm{mPa} \cdot \mathrm{s}$ (left); scheme of the gas emerging from the nozzles with $\alpha=15$ and $30^{\circ}$ in the respective gas channel angle and with the respective impact region (right).

As shown in Figure 3 (left, a-c), there was no significant change in the primary breakup morphology of the liquid jet from $\alpha=0^{\circ}$ to $30^{\circ}$. However, the only detectable difference can be seen on the liquid jet near the nozzle orifice. Comparing the high-speed camera images at this position from Figure 3 (a) to (b), a straight emerging jet without disturbances or formation of instabilities near the nozzle orifice is detectable (red mark). A further increase up to $\alpha=30^{\circ}$, results in a shorter stable liquid jet (see Figure 3 (c)).

This effect may be explained by the gas channel angle, leading to a velocity component in radial direction and thus to radial forces stabilizing the jet. For $\alpha=15^{\circ}$, the radial component is comparably low in value, but has a significant high impact area (see Figure 3 (right, $\left.15^{\circ}\right)$ ). For increasing $\alpha$ to $30^{\circ}$, the radial force increases, but the stabilizing impact area is reduced, as presented in Figure 3 (right, $30^{\circ}$ ).

The stabilization inhibits the formation of the Kelvin-Helmholtz instabilities (KHIs) that normally develops near the nozzle orifice. In an additional set of experiments, the necessary gas mass flow to form a $\mathrm{KHI}$ within the region of the red mark was investigated. 

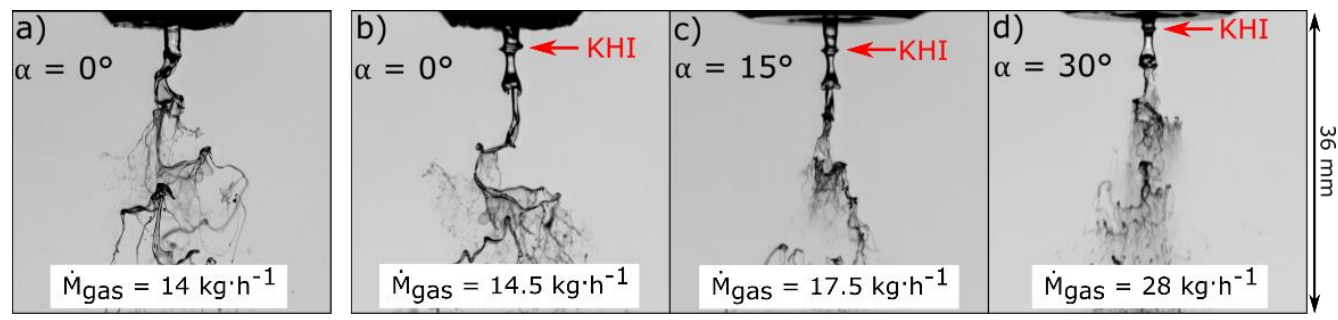

Figure 4. High-speed camera images of primary jet breakup at $p_{\text {sys }}=1$ bar with $\eta_{\text {liq }}=200 \mathrm{mPa} \cdot \mathrm{s}$ for: $\mathrm{a}$ ) $\alpha=0^{\circ}$ and $\mathrm{v}_{\mathrm{gas}, \mathrm{KHI}}=70 \mathrm{~m} \cdot \mathrm{s}^{-1}$; b) $\alpha=0^{\circ}$ and $\mathrm{v}_{\mathrm{gas}, \mathrm{KHI}}=72.5 \mathrm{~m} \cdot \mathrm{s}^{-1}$; c) $\alpha=15^{\circ}$ and $\mathrm{v}_{\mathrm{gas}, \mathrm{KHI}}=87.5 \mathrm{~m} \cdot \mathrm{s}^{-1}$; as well as d) $\alpha=30^{\circ}$ and $V_{\text {gas }, \mathrm{KHI}}=140 \mathrm{~m} \cdot \mathrm{s}^{-1}$.

The data in Figure 4 show, that with increasing gas channel angle, a higher velocity component stabilizes the liquid jet. As a result, a higher gas mass flow is needed to form the $\mathrm{KHI}$ for increasing gas channel angle.

\section{(ii) Influence of dynamic viscosity and system pressure on droplet size for different gas channel angles}

For a quantitative comparison of the resulting integral Sauter mean diameter utilizing 3 different gas channel angles, radial PDA measurements were performed for varying dynamic viscosities, gas velocities and system pressures. In order to indicate the resulting influences more clearly, the calculated $I_{32, m}$ values are displayed in Figure 5 (left).
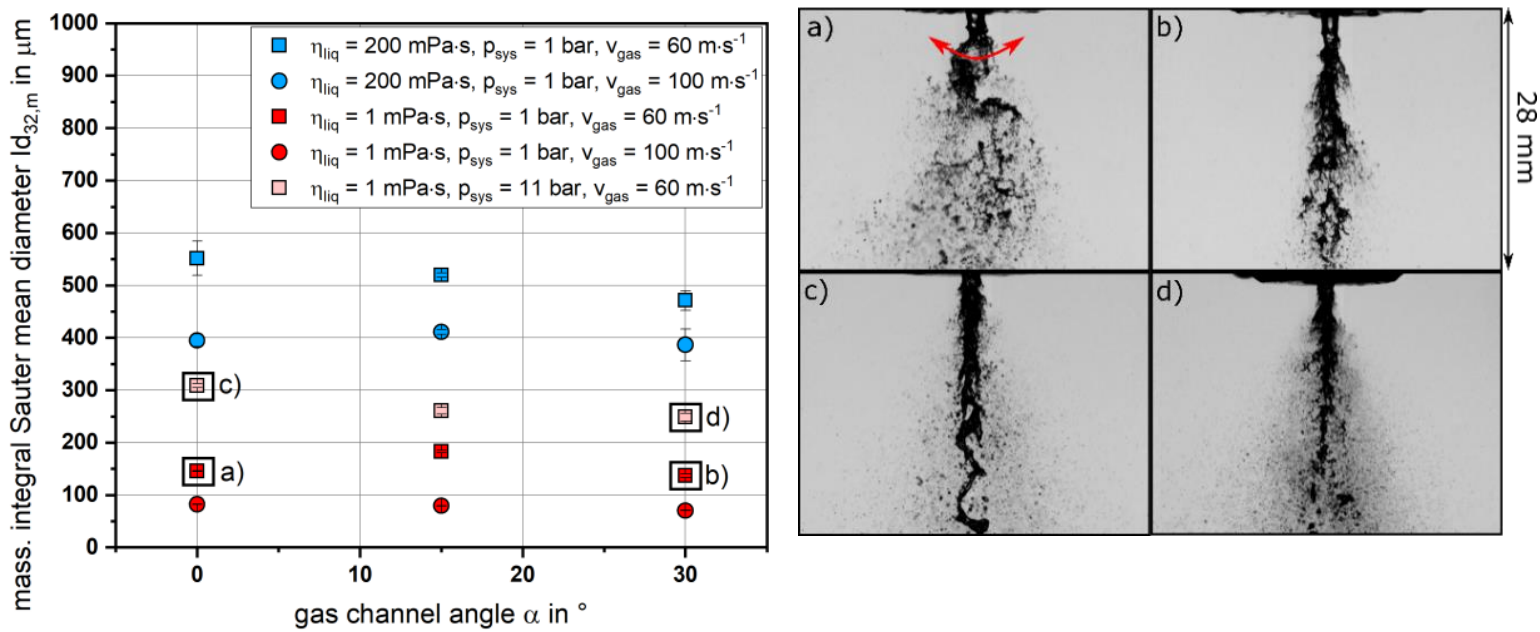

Figure 5. Calculated $I_{32, m}$ values for varying gas channel angles $\alpha=0,15$ and $30^{\circ}$ as a function of the dynamic viscosity, gas velocity and system pressure (left); high-speed camera images of the primary jet breakup for $\eta_{\text {liq }}=1$ $\mathrm{mPa} \cdot \mathrm{s}, \mathrm{v}_{\text {gas }}=60 \mathrm{~m} \cdot \mathrm{s}^{-1}$ at: a) $p_{\text {sys }}=1$ bar, $\alpha=0^{\circ}$ (flapping instability 1 ); b) $p_{\text {sys }}=1$ bar, $\alpha=30^{\circ}$; ) $p_{\text {sys }}=11$ bar, $\alpha=$ $0^{\circ}$; and d) $p_{\text {sys }}=11$ bar, $\alpha=30^{\circ}$ (right).

As presented in Figure 5 (left), for all gas channel angles it can be stated: For increasing liquid viscosity, an increase in droplet size was detected for both gas velocities under investigation. The damping effects of the liquid at higher viscosity explain this effect.

An increase in gas velocity from $v_{\text {gas }}=60$ to $100 \mathrm{~m} \cdot \mathrm{s}^{-1}$ leads to a reduction in $\mathrm{Id}_{32, \mathrm{~m}}$ for both viscosities. This effect can be explained by the higher aerodynamic forces, enhancing the jet breakup and droplet formation.

For increasing system pressure $p_{\text {sys, }}$, when applying the pressure-adapted nozzles approach, an increase in the droplet size was detected (see Figure 5 (right, c)). This result corresponds

\footnotetext{
${ }^{1}$ As the results of $\eta_{\text {liq }}=1 \mathrm{mPa} \cdot \mathrm{s}$ and $\mathrm{v}_{\text {gas }}=60 \mathrm{~m} \cdot \mathrm{s}^{-1}$ show lower values at $\alpha=0^{\circ}$ compared to $\alpha=15^{\circ}$, it has to be mentioned, that for $\alpha=0^{\circ}$, a flapping primary instability was developed (see Figure 5 (right, a)), leading to a different breakup morphology and to smaller droplets as for $\alpha=15^{\circ}$, which was in accordance with Sänger et al. [8].
} 
to previous investigations concerning atomizers with straight gas channels [16]. The effect may be explained by the stronger deceleration of the gas phase by entrainment of surrounding gas with increased system pressure with the given nozzle configuration.

In general, an increase of gas channel angle shifts the $\mathrm{Id}_{32, \mathrm{~m}}$ towards smaller values for low gas velocity $v_{\text {gas }}=60 \mathrm{~m} \cdot \mathrm{s}^{-1}$. This effect was observed for all liquid viscosities and system pressures investigated. As the gas momentum flow $J_{\text {gas }}$ was constant for all $\alpha$, the decrease in the droplet size with increasing gas channel angle may also be explained by the increase in the local gas velocity near the liquid jet.

For gas velocity $v_{\text {gas }}=100 \mathrm{~m} \cdot \mathrm{s}^{-1}$, the effect of the gas channel angle was found to be negligible for both dynamic viscosities investigated. As reported in literature, the effect of $J_{\text {gas }}$ on the resulting droplet size weakens with increasing $J_{\text {gas }}$ [24-26]. For high $J_{\text {gas }}$, the acceleration of axial velocity, due to an increase in gas channel angle, cannot induce a relevant effect on the liquid jet break up and resulting droplet size.

\section{Conclusions}

This study investigated the influence of the gas channel angle at different gas velocity (i.e. GLR), dynamic viscosity and system pressure (applying pressure-adapted nozzles) on the spray quality $\left(\mathrm{d}_{32}, \mathrm{Id}_{32, \mathrm{~m}}\right)$ of coaxial gas-assisted atomizers operated at a liquid mass flow of $\dot{M}_{\text {liq }}=20 \mathrm{~kg} \cdot \mathrm{h}^{-1}$. The atomizer geometry was kept similar, except that the gas channel angle was changed in steps of $\alpha=0^{\circ}, 15^{\circ}$ and $30^{\circ}$. Two different gas velocities ( $v_{\text {gas }}=60 / 100 \mathrm{~m} \cdot \mathrm{s}^{-}$ $\left.{ }^{1}\right)$ were investigated by changing the gas mass flow (i.e., GLR). The dynamic viscosity was varied by applying water and a glycerol/water mixture with $\eta_{\text {liq }}=200 \mathrm{mPa}$. . The measurements were performed at two system pressure levels ( $p_{\text {sys }}=1 / 11$ bar) utilizing pressure-adapted nozzles in order to keep $v_{\text {gas }}, \dot{M}_{\text {gas }}$ and GLR constant. High-speed camera images were used to observe the primary breakup and to explain local measurements of droplet size performed by a phase Doppler anemometer. The results of the experiments can be summarized as follows:

- For all investigated gas channel angles, an increase in gas velocity, as well as a reduction of liquid viscosity resulted in smaller droplet size. The increase of system pressure, applying pressure adapted nozzles, led to larger droplets.

- For increasing the gas channel angle, a decrease in the droplet size was detected for a gas velocity of $v_{\text {gas }}=60 \mathrm{~m}^{-1}$. This is caused by the gas jet impact on the liquid jet, leading to increased local gas velocities and thus aerodynamic forces.

- For all investigated gas channel angles, a stabilized region on the liquid jet near the nozzle orifice was detected, inhibiting the formation of Kelvin-Helmholtz instabilities. With increasing gas channel angle, the stabilized area decreased, but the necessary gas mass flow to form the $\mathrm{KHI}$ increased significantly due to an increase in the radial stabilizing forces.

- For increased gas velocity of $v_{\text {gas }}=100 \mathrm{~m} \cdot \mathrm{s}^{-1}$, the influence of the gas channel angle was negligibly small and independent of the investigated viscosity.

\section{Acknowledgments}

The authors gratefully acknowledge the financial support by the Helmholtz Association of German Research Centers (HGF) in the context of the research program, Materials and Technologies for the Energy Transition (MTET). The present work contributes to the Helmholtz Virtual Institute for Gasification Technology-HVIGasTech (VH-VI-429) (http://www.hvigastech.org/). 


\section{Nomenclature}

$\begin{array}{llllll}A_{\text {gas }} & \text { orifice area }\left[\mathrm{mm}^{2}\right] & A_{i} & \text { area i }\left[\mathrm{mm}^{2}\right] & b & \text { tube thickness }\left[\mathrm{mm}^{2}\right] \\ d_{D E H S} & \text { diameter }[\mu \mathrm{m}] & D_{\text {gas }} & \text { diameter }[\mathrm{mm}] & D_{\text {liq }} & \text { diameter }[\mathrm{mm}] \\ G L R & \text { Gas-to-Liquid ratio }[-] & I d_{32} & \text { diameter }[\mu \mathrm{m}] & I d_{32, m} & \text { diameter }[\mu \mathrm{m}] \\ J_{\text {gas }} & \text { momentum flow }[\mathrm{N}] & \dot{m}_{i} & \text { mass flux }\left[\mathrm{kg} \cdot \mathrm{s}^{-1} \cdot \mathrm{m}^{-2}\right] & \dot{M}_{\text {gas }} & \text { mass flow }\left[\mathrm{kg} \cdot \mathrm{s}^{-1}\right] \\ \dot{M}_{\text {liq }} & \text { mass flow }\left[\mathrm{kg} \cdot \mathrm{s}^{-1}\right] & p_{\text {sys }} & \text { pressure }[\mathrm{bar}] & T & \text { temperature }\left[{ }^{\circ} \mathrm{C}\right] \\ V_{a b s} & \text { velocity }\left[\mathrm{m} \cdot \mathrm{s}^{-1}\right] & V_{\text {gas }} & \text { velocity }\left[\mathrm{m} \cdot \mathrm{s}^{-1}\right] & V_{\text {gas }, K H I} \text { velocity }\left[\mathrm{m} \cdot \mathrm{s}^{-1}\right] \\ V_{\text {liq }} & \text { velocity }\left[\mathrm{m} \cdot \mathrm{s}^{-1}\right] & V_{z} & \text { velocity }\left[\mathrm{m} \cdot \mathrm{s}^{-1}\right] & V_{\text {gas }} & \text { volume flow }\left[\mathrm{m}^{3} \cdot \mathrm{h}^{-1}\right] \\ x, y, z & \text { position }[\mathrm{mm}] & \alpha & \text { channel angle }\left[{ }^{\circ}\right] & \eta_{\text {liq }} & \text { viscosity }[\mathrm{mPa} \cdot \mathrm{s}] \\ \rho_{\text {gas }} & \text { density }\left[\mathrm{kg} \cdot \mathrm{m}^{-3}\right] & \rho_{\text {liq }} & \text { density }\left[\mathrm{kg} \cdot \mathrm{m}^{-3}\right] & \sigma & \text { surface tension }\left[\mathrm{kg} \cdot \mathrm{s}^{-2}\right]\end{array}$

\section{References}

[1] Jakobs, T., Djordjevic, N., Fleck, S., Mancini, M., Weber, R., and Kolb, T. "Gasification of high viscous slurry R\&D on atomization and numerical simulation." Applied Energy Vol. 93 (2012): pp. 449-456. DOI 10.1016/j.apenergy.2011.12.026.

[2] Chigier, N. and Faragó, Z. "Morphological Classification of Disintegration of Round Liquid Jets in a Coaxial Air Stream." Atomization and Sprays Vol. 2 No. 2 (1992): pp. 137-153.

[3] Lasheras, J. C., Villermaux, E., and Hopfinger, E. J. "Break-up and atomization of a round water jet by high-speed annular air jet." Journal of Fluid Mechanics Vol. 357 (1998): 351 379. DOI 10.1017/S0022112097008070.

[4] Lorenzetto, G. E. and Lefebvre, A. H. "Measurements of Drop Size on a Plain-Jet Airblast Atomizer." AIAA Journal Vol. 15 No. 7: pp. 1006-1010.

[5] Jasuja, A. K. "Plain-Jet Airblast Atomization of Alternative Liquid Petroleum Fuels Under High Ambient Air Pressure Conditions." The american society of mechanical engineers No. 3 (1982).

[6] Rizk, N.K and Lefebvre, A.H. "Spray characteristics of plain-jet airblast atomizers." ASME Vol. 634 No. 106 (1984).

[7] Schmidt, P. and Walzel, P. "Zerstäuben von Flüssigkeiten." Chemie Ingenieur Technik Vol. 52 No. 4 (1980): pp. 304-311. DOI 10.1002/cite.330520405.

[8] Sänger, A., Jakobs, T., Djordjevic, N., and Kolb, T. "Effect of primary instability of a high viscous liquid jet on the spray quality generated by a twin-fluid atomizer." ILASS Europe 2014 Bremen, 26th Annual Conference on Liquid Atomization and Spray Systems. DOI 10.5445/IR/1000129940.

[9] Nasr, G. G., Yule, Andrew J., and Bendig, L. Industrial sprays and atomization: Design, analysis and applications. Springer, London, New York (2002).

[10] Fleck, S., Santo, U., Hotz, C., Jakobs, T., Eckel, G., Mancini, M., Weber, R., and Kolb, T. "Entrained flow gasification Part 1: Gasification of glycol in an atmospheric-pressure experimental rig." Fuel Vol. 217 (2018): pp. 306-319. DOI 10.1016/j.fuel.2017.12.077.

[11] Kim, K. Y. and Marshall, W. R. "Drop-Size Distributions from Pneumatic Atomizers." A. I. CH. E. Journal Vol. 17 No. 3: pp. 575-584.

[12] Yuan, K., Chen, L., and Wu, C. "Study on characteristics of different types of nozzles for coal-water slurry atomization." Journal of Thermal Science Vol. 10 No. 4 (2001).

[13] Carisson, P., Gebart, R., Grönberg, C., Marklund, M., Risberg, M., Wiinikka, H., and Öhrman, O. "Spatially resolved measurements of gas composition in a pressurised black liquor gasifier." Environmental Progress \& Sustainable Energy Vol. 28 No. 3 (2009): pp. 316-323. 
[14] Hardalupas, Y. and Whitelaw, J. H. "Characteristics of sprays produced by coaxial airblast atomizers." Journal of Propulsion and Power Vol. 10 No. 4 (1994): pp. 453-460. DOI 10.2514/3.23795.

[15] Varga, C. M., Lasheras, J. C., and Hopfinger, E. J. "Atomization of a small-diameter liquid jet by a high-speed gas stream." American Physical Society (ADS) Vol. 54 (2001).

[16] Wachter, S., Jakobs, T., and Kolb, T. "Experimental investigation on the influence of system pressure on resulting spray quality and jet breakup applying pressure adapted twin-fluid nozzles." International Journal of Multiphase Flow Vol. 125 (2020): p. 103189. DOI 10.1016/j.jmultiphaseflow.2019.103189.

[17] Wachter, S., Jakobs, T., and Kolb, T. "Towards system pressure scaling of gas assisted coaxial burner nozzles - An empirical model." Applications in Energy and Combustion Science Vol. 5 (2021): p. 100019. DOI 10.1016/j.jaecs.2020.100019.

[18] Albrecht, H.-E. Laser doppler and phase doppler measurement techniques. Springer, Berlin, New York (2003).

[19] Searle, G.F.C. "Simple Viscometer for Very Viscous Liquids." Proceedings of the Cambridge Philosophical Society, Mathematical and physical sciences Vol. 1912.

[20] du Nouy, P. L. "An Interfacial Tensiometer for Universal use." The Journal of General Physiology Vol. 7 No. 5 (1925): pp. 625-631. DOI 10.1085/jgp.7.5.625.

[21] Araneo, L., Damaschke, N., and Tropea, C. "Measurement and Prediction of the Gaussian Beam Effect in the PDA." Springer (2002): pp. 189-208.

[22] Kapulla, R. and Najera, S. B. "Operation conditions of a phase Doppler anemometer: droplet size measurements with laser beam power, photomultiplier voltage, signal gain and signal-to-noise ratio as parameters." Measurement Science and Technology Vol. 17 No. 1 (2006): pp. 221-227. DOI 10.1088/0957-0233/17/1/034.

[23] Tropea, C., Yarin, A. L., and Foss, J. F. Handbook Of Experimental Fluid Mechanics. Springer Berlin Heidelberg (2007).

[24] Lefebvre, A.H. "Twin-Fluid atomization Factors influencing mean drop size." Atomization and Sprays Vol. 2 (1992): pp. 101-119.

[25] Liu, H.-F., Li, W.-F., Gong, X., Cao, X.-K., Xu, J.-L., and Chen, X.-L. "Effect of liquid jet diameter on performance of coaxial two-fluid airblast atomizers." Chemical Engineering and Processing: Process Intensification No. 45 (2006): pp. 240-245. DOI 10.1016/j.cep.2005.08.003.

[26] Kim, K. Y. and Marshall, Jr., W. R. "Drop-Size Distributions from pneumatic atomizers." AlChE Journal Vol. 17 No. 3 (1971). 